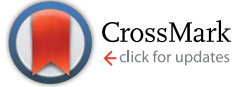

Cite this: RSC Adv., 2015, 5, 107001

Received 26th August 2015 Accepted 8th December 2015

DOI: $10.1039 / \mathrm{c} 5 \mathrm{ra17300k}$

www.rsc.org/advances

\section{Processing and characterization of large diameter ceramic SiCN monofilaments from commercial oligosilazanes $\uparrow$}

\begin{abstract}
O. Flores, ${ }^{\text {a R. K. Bordia, }}{ }^{\text {b }}$ S. Bernard, ${ }^{\text {C }}$ T. Uhlemann, ${ }^{a}$ W. Krenkel ${ }^{a}$ and G. Motz ${ }^{* a}$
This work reports the processing of large diameter ceramic SiCN monofilaments via the precursor route using two chemically different polysilazanes ML33S and HTTS self-synthesized from respective commercially available oligosilazanes. The melt-spinning of continuous polymer fibers with controllable diameters from 35 to $150 \mu \mathrm{m}$ and their pyrolysis to ceramic SiCN fibers is not influenced by differences in the chemical structure of the polysilazanes. In contrast, the necessary e-beam curing dose is reduced by Si-vinyl groups from 600 kGy for ML33S (vinyl free) to 200 kGy for HTTS derived polymer fibers. The curing step leads to an enhanced handleability important for further pyrolysis at $1100{ }^{\circ} \mathrm{C}$ in nitrogen and to an increase in ceramic yield. The resulting ceramic SiCN fibers from both systems have similar mechanical and thermal behavior, indicating quite a low influence of the polysilazane type on these properties. For the first time a comprehensive investigation of the effect of fiber diameter on the tensile strength is reported for SiCN fibers. The average strength increases from 800 MPa for $90 \mu \mathrm{m}$ diameter fibers to $1600 \mathrm{MPa}$ for the $30 \mu \mathrm{m}$ diameter fibers. Bend Stress Relaxation (BSR) tests demonstrated that no stress relaxation occurs up to $1000{ }^{\circ} \mathrm{C}$ for $\mathrm{SiCN}$ monofilaments and the creep resistance is equal to or better than commercially available $\mathrm{SiC}$ monofilaments produced by chemical vapour deposition (CVD). The oxidation resistance is also comparable to commercially available oxygen free CVD SiC fibers (SCS-6). The ceramic fibers in this study were pyrolyzed at low temperature $\left(1100{ }^{\circ} \mathrm{C}\right)$ and have high oxygen content (13 to $29 \mathrm{wt} \%$ ). The high temperature creep resistance and oxidation resistance is expected to improve if the oxygen content is reduced and the pyrolysis temperature increased.
\end{abstract}

\section{Introduction}

Lightweight thermostructural materials are needed in next generation aero turbine engine components to improve the energy efficiency due to weight reduction and increase of the operating temperature. They are also needed for other advanced applications including heat exchangers, rocket propulsion, fusion reactors and UHTC parts for supersonic and hypersonic vehicles. In these applications, ceramic fibers play an important role as reinforcements of metallic and ceramic matrices to realize the manufacturing of composite materials with low density and for high temperature applications.

Research activities in the field of high performance nonoxide ceramic fibers led, over the last 50 years, to the development of commercially available chemical vapour deposited

\footnotetext{
${ }^{a}$ Ceramic Materials Engineering, University of Bayreuth, D-95447 Bayreuth, Germany. E-mail: guenter.motz@uni-bayreuth.de

${ }^{b}$ Department of Materials Science and Engineering, Clemson University, SC 296340971, Clemson, USA

${ }^{c} I E M$ (Institut Europeen des Membranes), UMR 5635 (CNRS-ENSCM-UM), Universite Montpellier, Place E. Bataillon, F-34095, Montpellier, France

$\dagger$ On the occasion of Prof. Dr Gerhard Röwer's $75^{\text {th }}$ birthday.
}

(CVD) SiC monofilaments ${ }^{\mathbf{1 - 3}}$ and three generations of SiC fibers based on polymer derived ceramics (PDCs).,4-6 These high performance fibers comprise not only superior mechanical properties, such as tensile strength $>2 \mathrm{GPa}$ and stiffness, but also thermal stability at temperatures higher than $800{ }^{\circ} \mathrm{C}$, which are essential for the reinforcement of materials based on metallic and ceramic matrix composites (MMCs and CMCs respectively).

For MMCs applications, such as combustion engines and high efficiency turbines, titanium matrix composites (TMCs) reinforced with CVD SiC monofilaments are promising candidates, as they combine the high strength, stiffness and creep resistance of SiC monofilaments with the high ductility, toughness and corrosion resistance of titanium alloys., ${ }^{7,8}$ Because SiC fibers are generally reactive with titanium alloys at high temperatures, fabrication processes that allow a controlled chemical reaction with the metal matrix, mainly dominated by diffusion, enables the formation of a strong fiber-matrix interface and good adhesion. This good adhesion is needed for the efficient load transfer from the metal matrix to the SiC fibers. The major obstacle for the application of TMCs in the industry is the high material cost of monofilament SiC fibers. 
They are among the most expensive ceramic fibers with prices up to $\sim 8000 €$ per $\mathrm{kg}$ (11 000 US per kg).,2,89

In contrast, the continuous processing of fine diameter fibers from inorganic polymers is still the most attractive method for the manufacturing of cost-effective non-oxide ceramic fibers. Ceramic fibers from SiCN systems, such as polysilazanes, comprise good oxidation stability up to $\sim 1500{ }^{\circ} \mathrm{C}$ (due to the nitrogen content) and corrosion resistance in acids and bases. Beside this they offer a remarkable cost reduction, due to relatively inexpensive precursors, use of low e-beam doses for their curing and relatively simple processing. ${ }^{2,10,11}$

In this paper we report on the processing and properties of large diameter SiCN monofilaments made from preceramic polymers as an alternative to CVD SiC monofilaments. Two different types of meltable polysilazanes with tailored properties were recently developed in our chair. ${ }^{12,13}$ These polymers open new opportunities for cost effective processing of ceramic SiCN fibers with larger diameters as demonstrated in this investigation.

Therefore, the aim of this work was to melt spin tailored polysilazanes fibers of large diameter, to investigate the influence of the electron beam irradiation dose on the curing of melt spun green fibers and to study the pyrolysis of these green polymeric fibers to ceramic fibers. Finally, the mechanical and thermal properties, including strength, strength distribution, creep resistance and oxidation behavior, of these fibers have been investigated and compared to commercially available SiC fibers.

\section{Experimental procedure}

Both polymers, ML33S and HTTS, used for the processing of ceramic SiCN fibers are produced by a selective chemical crosslinking of two commercially available liquid oligosilazanes ML33 and HTT1800, respectively, which were purchased from Clariant Advanced Materials GmbH (Sulzbach, Germany) (Fig. 1).

Both tailored polymers are meltable solids, having suitable viscoelasticity and thermal stability up to $170{ }^{\circ} \mathrm{C}$ for the meltspinning of fibers. More details about the synthesis and characterization of ML33S and HTTS, including their rheology and thermal stability, have been reported elsewhere. ${ }^{\mathbf{1 2 - 1 4}}$

\subsection{Processing of ceramic SiCN monofilaments}

Monofilaments from ML33S or HTTS polysilazanes were meltspun in a lab-scale gas pressure melt spinning equipment. About $8 \mathrm{~g}$ of the polymer were filled in the vessel of the spin equipment, melted at temperatures between 110 and $130{ }^{\circ} \mathrm{C}$,
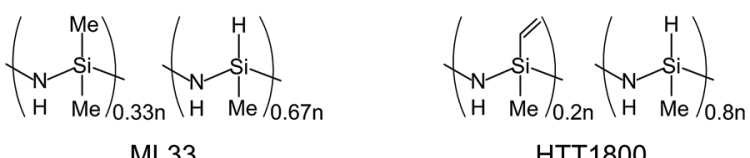

Fig. 1 Simplified chemical structures of the liquid ML33 and HTT1800 oligosilazanes. evacuated to remove gas bubbles and left at the desired temperature for 15 minutes to ensure a constant and uniform temperature. Afterwards, nitrogen over pressure was applied to allow the melt-spinning of filaments through a spinneret followed by winding of the fibers. Monofilaments with diameter > $70 \mu \mathrm{m}$ were melt spun through a spinneret with a single capillary having a diameter of $800 \mu \mathrm{m}$. To investigate the dependence of the strength of the ceramic fibers on the diameter, filaments with diameter $<70 \mu \mathrm{m}$ were also melt spun by using a spinneret with 7 holes, each one with a diameter of $400 \mu \mathrm{m}$.

For the investigation of the electron beam irradiation dose needed to render the precursor unmeltable, cylindrical samples having diameter of $20 \mathrm{~mm}$ and thickness of $10 \mathrm{~mm}$ were prepared from ML33S or HTTS polysilazanes by melting the polymer in nitrogen atmosphere in a silicone mold. The samples were packed under nitrogen atmosphere in a polyethylene (PE) plastic sheet and sent to the company BetaGamma-Service GmbH, Saal, Germany. An acceleration voltage of $10 \mathrm{MeV}$ and doses up to $1000 \mathrm{kGy}$ were applied for the electron beam curing experiments of the samples.

The gel fraction of the precursors after irradiation was determined based on the German standard DIN 16892. ${ }^{15}$ About $0.25 \mathrm{~g}$ of the cured sample powder was solved in toluene and refluxed for 4 hours at $80{ }^{\circ} \mathrm{C}$. After filtration through a regenerated cellulose filter with a pore size of $0.2 \mu \mathrm{m}$, the undissolved fraction remaining on the filter was dried and weighed for the calculation of the gel fraction according to the following equation:

$$
G=\frac{m_{2} \times 100}{m_{1}}
$$

where $G$ is the gel fraction in $\%, m_{1}$ the weight of the cured sample powder before dissolving in toluene and $m_{2}$ the weight of the dried undissolved part after filtration. In order to complement the gel fraction analysis, e-beam cured cylindrical samples were pyrolysed in nitrogen atmosphere up to $1000{ }^{\circ} \mathrm{C}$ with a heating rate of $10 \mathrm{~K} \mathrm{~min}^{-1}$ to amorphous SiCN ceramics and their meltability was analysed.

For the investigation of the transition from the polymer to amorphous ceramic SiCN material thermal gravimetric analysis (TGA) was performed, using a Linseis L81 A1550 unit (Linseis, Germany). Approximately $10 \mathrm{mg}$ of the sample was heated from 25 to $1300{ }^{\circ} \mathrm{C}$ with a heating rate of $5 \mathrm{~K} \mathrm{~min}^{-1}$ in nitrogen atmosphere. The ceramic yield was calculated from the mass change of the material after the thermal treatment.

Based on the curing results obtained from the cylindrical samples, the collected monofilaments were cured at BGS $\mathrm{GmbH}$, Saal, with an acceleration voltage of $10 \mathrm{MeV}$ and doses up to $600 \mathrm{kGy}$. After curing, the fibers were converted into amorphous ceramic SiCN fibers by continuous pyrolysis in a tubular furnace (model GERO Gero FA100-500/13) equipped with a bobin at each end of the furnace tube. The pyrolysis was conducted at a maximum temperature of $1100{ }^{\circ} \mathrm{C}$ in nitrogen atmosphere. Cured green fibers were continuously pulled through the furnace using a fiber winding unit with a velocity of $0.3 \mathrm{~cm} \min ^{-1}$. The elemental composition of the uncured, cured 
and of the ceramic SiCN fibers was analysed at Pascher Microanalytical Laboratory (Remagen, Germany).

\subsection{Properties of ceramic SiCN monofilaments}

Tensile tests were carried out for both the cured green and ceramic SiCN monofilaments at ambient conditions using a universal mechanical testing machine (Inspekt Mini, Hegewald \& Peschke GmbH, Germany). From each batch 40 samples were selected and their tensile strength was determined. According to DIN-ENV 1007-4 individual filaments were glued onto a split cardboard frame with a gauge length of $25 \mathrm{~mm} \cdot{ }^{16} \mathrm{~A}$ $20 \mathrm{~N}$ load cell was used with a cross-head speed of $4 \mathrm{~mm} \mathrm{~min}^{-1}$. Fiber diameters were determined prior to the mechanical test with an optical microscope (Zeiss, Axiotech 100) equipped with a camera for digital analysis of the picture. After the tensile test, filaments that broke in the extremities of the split cardboard frame were excluded from the analysis.

In order to measure the creep resistance of the amorphous ceramic SiCN fibers, the Bend Stress Relaxation (BSR) method developed by Morscher et al. ${ }^{17}$ was used for single monofilaments with diameter $>70 \mu \mathrm{m}$. Fibers were tied into a loop with a radius $R_{0}$ of $10 \mathrm{~mm}$ at room temperature and heated up in air or nitrogen atmosphere for 1 hour to temperatures ranging from 900 to $1200{ }^{\circ} \mathrm{C}$. After the thermal treatment of the sample, the fiber loop was cut at room temperature and the resulting radius of curvature $R_{\mathrm{a}}$ measured. To have a quantitative measurement of the creep resistance of the fibers, the BSR ratio $\left(m_{\mathrm{BSR}}(T, t)=1-R_{0} / R_{\mathrm{a}}\right)$ was calculated. For the evaluation of $m_{\mathrm{BSR}}, 4$ samples of each ceramic SiCN fiber charge were used for each test condition. The mean value of the $m_{\mathrm{BSR}}$ of these samples was used for the discussion.

The oxidation resistance of the ceramic SiCN fibers was investigated using the TGA equipment (Linseis, L81/1550), and compared with commercial ceramic SiC fibers, type SCS 6 . Monofilaments were cut in samples of $2 \mathrm{~cm}$ in length and placed in an alumina crucible. The samples were heated up to a maximum temperature ranging from 900 to $1300{ }^{\circ} \mathrm{C}$, heating rate of $10 \mathrm{~K} \mathrm{~min}^{-1}$ and a dwell time up to 12 hours under flowing oxygen $\left(5 \mathrm{~L} \mathrm{~min}^{-1}\right)$. After oxidation, the morphology and thickness of the oxide layer on the fiber was analysed by scanning electron microscopy (SEM, Zeiss, 1540EsB) coupled with an Energy Dispersive X-ray Spectrometer (EDS, Thermo Scientific, NORAN System 6).

\section{Results and discussion}

\subsection{Processing of polymer derived ceramic SiCN fibers}

Based on the molecular, thermal and rheological analysis of the polysilazanes manufactured by controlled cross-linking, ${ }^{12,13}$ continuous green fibers were processed in air, using the labscale melt spinning equipment. After the green fibers were spun in air and left for 3 hours on the spool in contact with air, the oxygen content of the fibers remains $<0.5 \mathrm{wt} \%$. The oxygen incorporation is due to the reaction between the surface of the fiber with the moisture in the environment ${ }^{18}$ as described by Hacker, ${ }^{11}$ who used the self-synthesized ABSE polysilazane for processing of ceramic SiCN fibers. Fig. 2 shows a large diameter melt spun monofilament wound on a spool.

For the processing of green fibers, based on prior knowledge in our laboratory, a viscosity of $5 \times 10^{3} \mathrm{~Pa}$ s was chosen to ensure a continuous viscoelastic flowability of the polymer. Based on rheological measurements, this required a processing temperature of about $50 \mathrm{~K}$ higher than the glass temperatures of the polymers. ${ }^{12,13}$ In addition to the viscosity and the spinneret hole diameter, the final diameter of the green fibers is controlled by the pull-off speed. Polymer monofilaments having diameters between $\sim 35$ and $150 \mu \mathrm{m}$ were successfully processed by adjusting the temperature (and hence the viscosity of the melt) between 110 and $120^{\circ} \mathrm{C}$ and by varying the pull-off speed between 10 and $30 \mathrm{~m} \mathrm{~min}^{-1}$.

The e-beam irradiation is not only crucial to turn the green fibers into infusible solids, but also improves their flexibility and handleability for further pyrolysis into ceramic fibers.

Commercially available $\mathrm{SiC}$ fibers require high electron beam doses, between 7500 and $20000 \mathrm{kGy} .{ }^{19}$ The irradiation dose to cross-link Hi-Nicalon fibers from polycarbosilane (PCS) can be reduced by the addition of vinyl sources, such as polyvinylsilane ${ }^{20,21}$ But the work about the influence of the irradiation dose on the cross-linking behavior of polyorganosilazanes is rather limited. ${ }^{22,23}$

Therefore the present investigations to determine the minimum e-beam dose are based on scientific works regarding the development of ceramic SiCN fibers from ABSE polysilazane. ${ }^{22}$ In order to quantify the curing results, the gel content of the polymer ML33S and HTTS fibers after irradiation was measured (using eqn (01)).

Fig. 3 demonstrates that the curing behavior of the polysilazanes strongly depends on their functional groups. Due to the absence of Si-vinyl groups in ML33S, the required dose for its curing is higher than that for HTTS. Hence, an e-beam dose $\geq 600 \mathrm{kGy}$ is required to reach a gel content of about $60 \%$ and to render the ML33S green fibers infusible. Melting tests performed with the polymers after curing confirm that ML33S

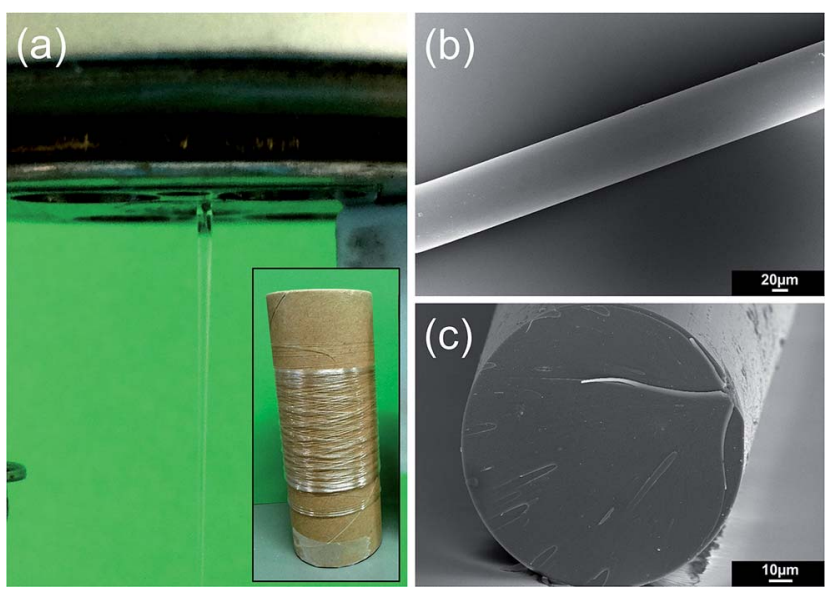

Fig. 2 (a) Melt spinning of polymer green monofilament and a spool with wound monofilaments. SEM micrographs of (b) the cross-section and (c) the surface of ML33S derived green monofilaments. 


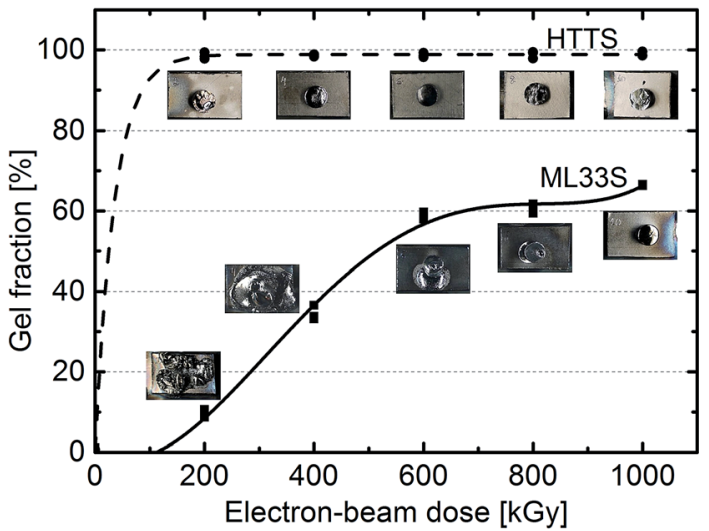

Fig. 3 Gel content of ML33S and HTTS polysilazanes after curing with electron beam doses up to $1000 \mathrm{kGy}$ and comparison with the melting test of the respective cured samples.

samples treated with e-beam doses greater than $600 \mathrm{kGy}$ maintain their shape (remain infusible).

HTTS already reaches a gel content of nearly $100 \%$ after treatment with a low dose of only $200 \mathrm{kGy}$ due to the highly reactive Si-vinyl groups. In contrast to the curing of ML33S, all HTTS samples showed a yellowish appearance, which is probably a sign of the formation of reactive free radicals or conjugated bondings. The melting test confirmed that all cured HTTS samples were already infusible even after treating with a very low dose of $200 \mathrm{kGy}$, which is enough to obtain infusible HTTS green fibers.

With the additional cross-linking of the precursors by using e-beam irradiation, their ceramic yield slightly increases due to the further reduction of volatile oligomers. In Fig. 4a the TGA curve indicates that a dose of only $200 \mathrm{kGy}$ to cure ML33S has small influence on the reduction of released volatile oligomers, occurring between 200 and $400{ }^{\circ} \mathrm{C}$. However with doses $\geq 400$ kGy this reduction is more pronounced and the ceramic yield for cured ML33S materials increases to up to $\sim 78 \mathrm{wt} \%$ in comparison to a ceramic yield of $70 \mathrm{wt} \%$ for the uncured ML33S. However the increase in the ceramic yield for the uncured (78 wt $\%$ ) to the e-beam cured HTTS samples ( $~ 82 \mathrm{wt} \%)$ is not significant (Fig. 4b).

These results clearly illustrate that the Si-vinyl groups reduce the necessary electron beam dose for the curing of HTTS derived green fibers significantly in comparison to the less reactive ML33S derived green fibers. Furthermore, while both types of melt spun uncured green fibers are brittle, especially the cured green fibers from HTTS appear more flexible and stronger, which is important for the subsequent pyrolysis process. After exposure to an e-beam dose of $600 \mathrm{kGy}$, cured green fibers from HTTS have a mean tensile strength of $65 \mathrm{MPa}$, while cured ML33S derived green fibers reached a mean strength of only $43 \mathrm{MPa}$.

Concerning the continuous pyrolysis of the cured fibers into ceramic fibers, a minimum diameter for the take-up spool used to pull the ceramic fibers leaving the furnace was chosen to avoid that the fibers with $d>70 \mu \mathrm{m}$ break on the spool. For this purpose, prior to the continuous pyrolysis, about 1 meter of the cured monofilaments with diameter $\sim 100 \mu \mathrm{m}$ were cut in samples with $20 \mathrm{~cm}$ length, deposited on a graphite boat and pyrolysed in a furnace at $1000{ }^{\circ} \mathrm{C}$ in nitrogen atmosphere for 1 hour. The pyrolysed monofilaments were bent until they broke and the mean value of the bending diameter prior to the breaking was taken as the minimum spool diameter used to pull the SiCN fibers.

After the continuous pyrolysis in a horizontal tubular furnace in nitrogen atmosphere the resulting ceramic SiCN fibers leave the furnace passing through the guide pulley before they are finally pulled on a spool with a diameter of $160 \mathrm{~mm}$ by a motor operated coiling unit (Fig. 5a and b). Fig. 5b shows a bundle of 3 pyrolysed ceramic monofilaments with a length of more than 10 meters on the spool.

For all investigated fiber batches continuous pyrolysis lead to amorphous ceramic SiCN fibers with regular and smooth surface. SEM micrograph of HTTS derived ceramic fibers confirms diameters up to $100 \mu \mathrm{m}$, with a dense core and without noticeable defects or pores (Fig. 6). Due to the similarity, micrographs of ML33S derived ceramic fibers are not shown.

The oxygen content of the processed amorphous ceramic SiCN fibers is similar or higher than for Nicalon fibers (Table 1).
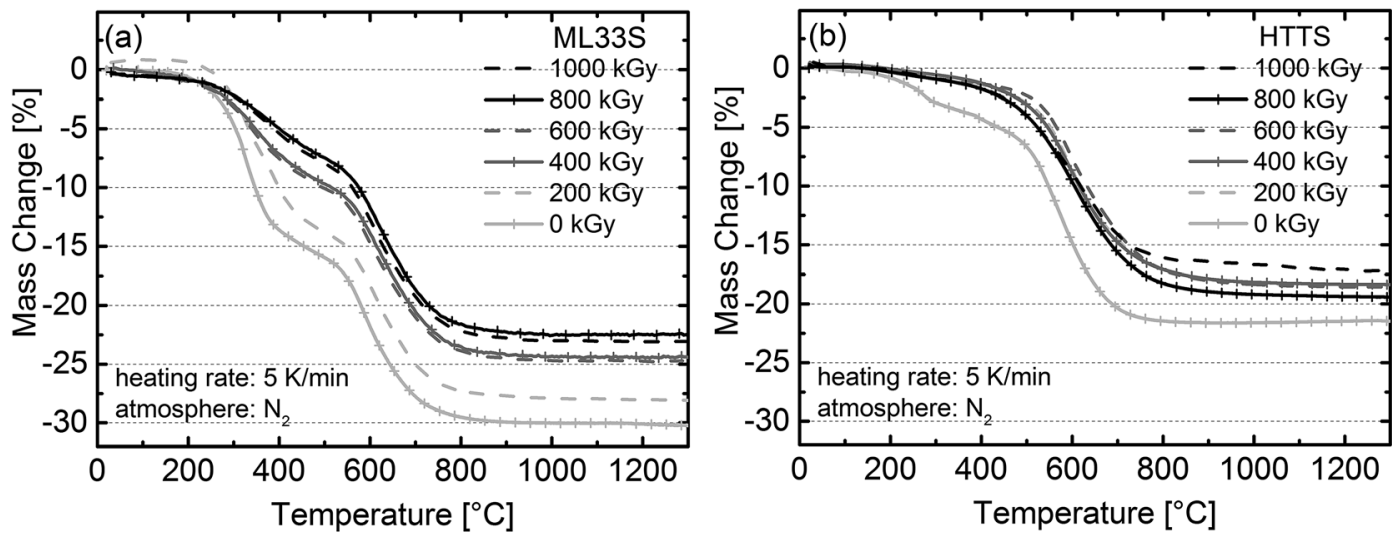

Fig. 4 The dependence of mass change during pyrolysis on the e-beam dose of (a) ML33S and (b) HTTS polysilazanes. 


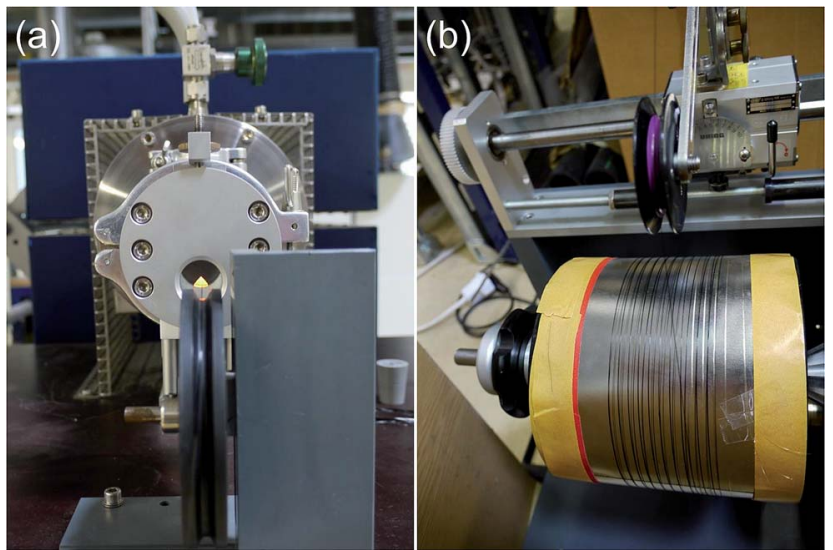

Fig. 5 (a) Ceramic SiCN fibers from HTTS with diameter of $\sim 100 \mu \mathrm{m}$ leaving the tubular furnace and (b) continuously pulled on the spool.

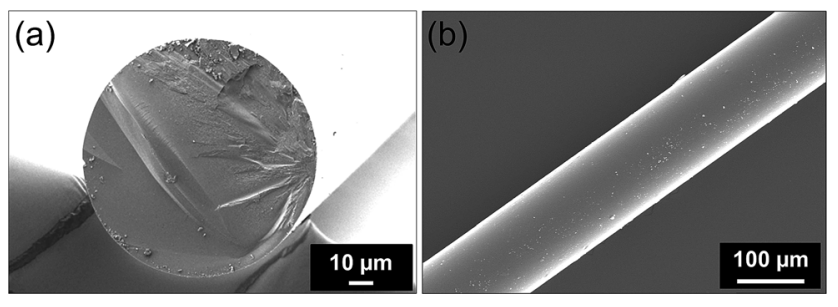

Fig. 6 SEM micrographs of (a) the cross section and (b) surface of amorphous ceramic SiCN fibers from HTTS.

Although the oxygen content of the uncured polymers is only $<0.5 \mathrm{wt} \%$, after their melt-spinning in air and curing with electron beam irradiation in inert atmosphere it increases to 3.5 and $4.7 \mathrm{wt} \%$ for ML33S and HTTS derived green fibers, respectively. After pyrolysis in nitrogen atmosphere the oxygen content of ML33S derived ceramic fibers reaches $\sim 13 \mathrm{wt} \%$ while HTTS derived ceramic fibers contain $\sim 29$ wt $\%$ oxygen. This high increase in oxygen content is due to the handling and long exposure of the cured fibers in air before they are pulled through the furnace at a very low velocity of $0.3 \mathrm{~cm} \mathrm{~min}^{-1}$, as described in Chapter 2.1.

During exposure in air, the nitrogen of the silazanes is replaced by oxygen. ${ }^{18}$ This fact becomes evident especially for HTTS derived fibers as a consequence of the higher content of moisture sensitive $\mathrm{Si}-\mathrm{H}$ groups. Beside this, vinyl groups are present in this precursor, which are activated during e-beam curing, distinguishable on the change in color from colorless to yellowish due to the formation of reactive radicals. Clearly, this enhanced reactivity also leads to an additional formation of Si-O bondings. ${ }^{21,22}$ More details about the influence of oxygen content in the creep and oxidation stability of the processed SiCN fibers will be later on discussed in Chapters 3.2.2 and 3.2.3.

\subsection{Mechanical and thermal properties of ceramic SiCN fibers}

3.2.1. Room temperature tensile strength and strength distribution. We measured the tensile strength of the pyrolyzed fibers which fail in a brittle manner. The strength of brittle materials is controlled by the size, shape and orientation (relative to stress) of the largest flaw. For brittle fibers, fiber diameter, fiber surface and the microstructure of the material have been shown to be the main factors that control the tensile strength. Therefore, the general observation that the measured strength of brittle fibers increases as the diameter decreases, according to earlier works from Griffith $^{24}$ with glass fibers, was tested with the processed ML33S and HTTS derived ceramic SiCN fibers with a broad range of diameters ( 230 to $100 \mu \mathrm{m})$. Due to the fact that the ceramic SiCN fibers are amorphous ceramic materials, the effect of fiber diameter is expected to be similar to that for the behavior of glass fibers. ${ }^{24}$

Fig. 7 shows the tensile strength of ML33S and HTTS derived ceramic SiCN fibers as a function of the fiber diameter. In the case of ML33S derived ceramic fibers, there is significant scatter in strength for fibers with a diameter between 40 and $50 \mu \mathrm{m}$, but the tendency to higher strength values with the reduction of the diameter is clearly illustrated. Such scatter results from the not optimized melt-spinning process. With this simple lab-scale gas pressure melt spinning equipment it is impossible to remove all gas bubbles from the polymer melt, which lead to pores within the resulting fibers. However, especially for HTTS derived ceramic fibers the effect of fiber diameter on tensile strength is much clear due to lower scatter. For both ceramic fiber types the tensile strength values are similar for the same diameter. While fibers with about $100 \mu \mathrm{m}$ have a tensile strength of $\sim 0.8 \mathrm{GPa}$, thinner fibers with a diameter of $30 \mu \mathrm{m}$ have a mean tensile strength as high as $\sim 1.5 \mathrm{GPa}$. A further reduction of the fiber diameter should lead to tensile strength values higher than 2 GPa. For comparison, the tensile strength of commercially available SCS-6 fibers is about $3.9 \mathrm{GPa}^{2}$ This very high value is a result of the CVD process, which leads to nearly defect free SiC

Table 1 Elemental composition and empirical formula of synthesized polysilazanes, their respective cured green fibers and ceramic fibers

\begin{tabular}{llllllll}
\hline & Structure & $\mathrm{Si}(\mathrm{wt} \%)$ & $\mathrm{C}(\mathrm{wt} \%)$ & $\mathrm{N}(\mathrm{wt} \%)$ & $\mathrm{O}(\mathrm{wt} \%)$ & $\mathrm{H}(\mathrm{wt} \%)$ & Empirical formula \\
\hline \multirow{2}{*}{ ML33S } & Uncured polymer & 43.7 & 24.0 & 23.8 & 0.4 & 8.1 & $\mathrm{SiC}_{1.28} \mathrm{~N}_{1.09} \mathrm{H}_{5.15}$ \\
& Cured polymer & 44.0 & 23.6 & 21.7 & 3.5 & 7.2 & $\mathrm{SiC}_{1.25} \mathrm{~N}_{0.99} \mathrm{O}_{0.14} \mathrm{H}_{4.55}$ \\
& Ceramic & 53.0 & 15.7 & 18.4 & 12.9 & $<0.05$ & $\mathrm{SiC}_{0.69} \mathrm{~N}_{0.70} \mathrm{O}_{0.43}$ \\
\multirow{2}{*}{ HTTS } & Uncured polymer & 42.4 & 26.2 & 23.3 & 0.4 & 7.6 & $\mathrm{SiC}_{1.44} \mathrm{~N}_{1.1} \mathrm{H}_{5.02}$ \\
& Cured polymer & 42.1 & 25.8 & 20.5 & 4.7 & 6.9 & $\mathrm{SiC}_{1.43} \mathrm{~N}_{0.98} \mathrm{O}_{0.20} \mathrm{H}_{4.56}$ \\
& Ceramic & 46.7 & 19.2 & 5.5 & 28.6 & $<0.03$ & $\mathrm{SiC}_{0.96} \mathrm{~N}_{0.23} \mathrm{O}_{1.07}$ \\
Nicalon $^{2}$ & Ceramic & 57 & 32 & - & 12 & - & -
\end{tabular}


fibers. Although the tensile strength value of the prepared ceramic SiCN fibers is still lower, the continuous processing of thick SiCN fibers with diameter $>70 \mu \mathrm{m}$ and tensile strength of $\sim 0.8 \mathrm{GPa}$ is a significant result and a crucial precondition for their use as reinforcement in metal matrix composites.

In order to better understand the mechanical behavior of these ceramic SiCN fibers, Weibull distribution analysis was used to analyze the fracture strength. Considering that identical specimens of brittle materials, such as ceramic fibers, show a large variation of tensile fracture stresses, the cumulative distribution function proposed by Weibull ${ }^{25}$ was used for a statistical characterization of the tensile strength for ceramic SiCN fibers made from ML33S and HTTS. The single parameter Weibull distribution leads to a failure probability given by:

$$
P=1-\exp \left[-\left(\frac{V}{V_{0}}\right)\left(\frac{\sigma}{\sigma_{0}}\right)^{m}\right]
$$

where $m$ is the Weibull modulus, $\mathrm{V}$ the tested volume, $\sigma$ the failure strength and $V_{0}$ and $\sigma_{0}$ are scale parameters. If the tested volume is constant, i.e. when the gauge length and the diameter of the fibers are assumed constant, eqn (02) can be rearranged and reduced to:

$$
\ln \ln \left(\frac{1}{1-P}\right)=m \ln \sigma-m \ln \sigma_{0}
$$

The Weibull analysis of brittle fracture is based on the weakest link theory, which assumes that all materials contain inhomogeneities, such as pores or flaws, distributed randomly with a certain density per unit volume. If these defects are the origin of material's fracture then tensile failure is determined by the largest critical defect. ${ }^{25,26}$

In Fig. 8, the results of the Weibull analysis on the strength of the ceramic SiCN fibers are presented. Although it is known that the variation in diameter influences the volume variation when the tensile strength is measured using the same gauge length (in this work being $25 \mathrm{~mm}$ ) the single mode Weibull analysis was used and it was assumed that there is no volume variation as the fiber diameter changes.

The Weibull parameters, modulus $m$ and scale parameter $\sigma_{0}$ are presented in Table 2 . The Weibull parameters are similar for the two types of fibers. In spite of the diameter variation from 30 to $100 \mu \mathrm{m}$, the single mode Weibull distribution fits the strength data reasonably well. The mean strength of ML33S and HTTS derived ceramic fibers is about $1 \mathrm{GPa}$.

For further analysis of the strength distribution, the strength results were grouped in two ranges - fiber diameter less than 70 $\mu \mathrm{m}$ and greater than $70 \mu \mathrm{m}$. Weibull analysis was conducted separately for these two groups and the results are shown in Fig. 9. As can be seen, the Weibull modulus of higher diameter
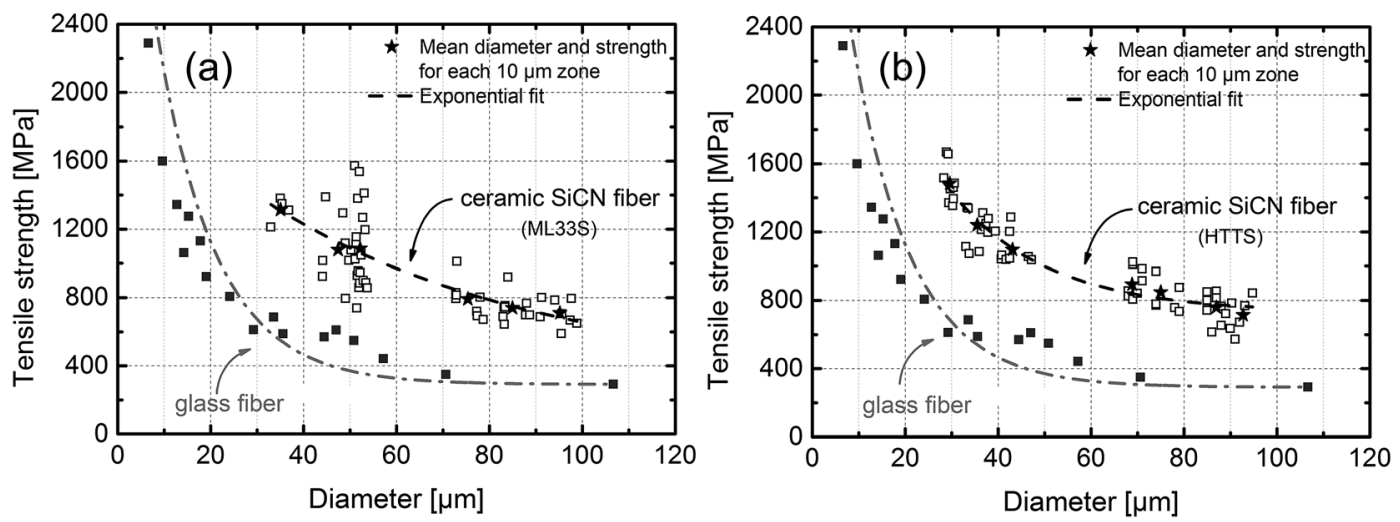

Fig. 7 Effect of fiber diameter on the tensile strength for (a) ML33S or (b) HTTS derived ceramic SiCN fibers compared to glass fibers. ${ }^{24}$
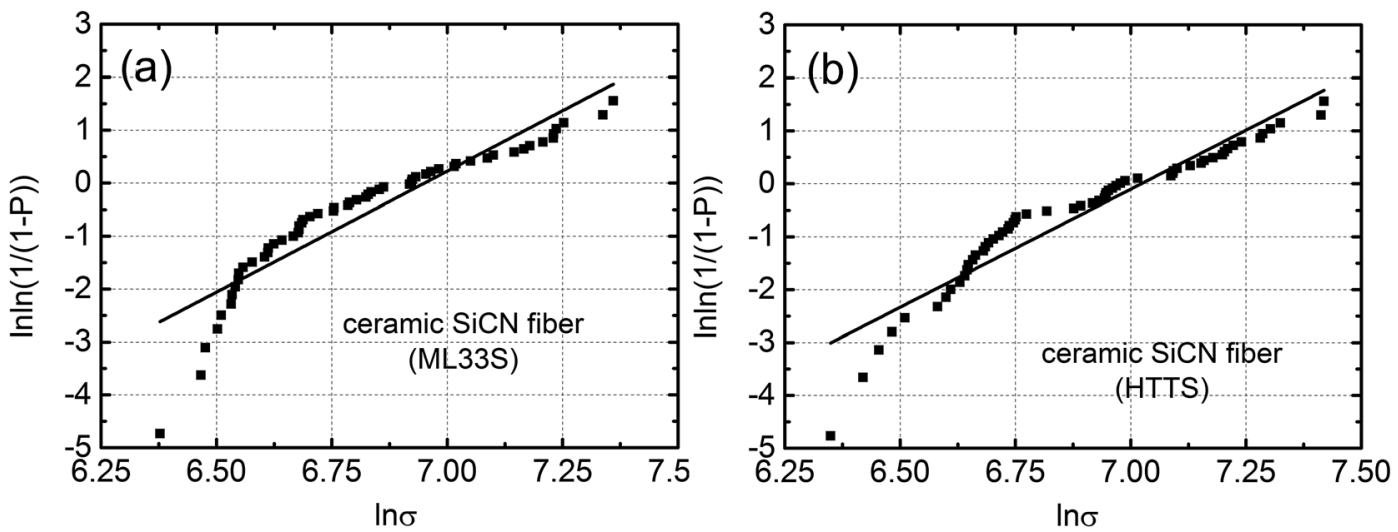

Fig. 8 Weibull analysis of (a) ML33S and (b) HTTS derived ceramic SiCN fibers with diameter between 30 and $100 \mu \mathrm{m}$. 
Table 2 Mean strength and Weibull parameters of ceramic SiCN fibers

\begin{tabular}{llllll}
\hline & & $\bar{d}$ & & \\
PDC & Fiber diameter $(\mu \mathrm{m})$ & $(\mu \mathrm{m})$ & $\bar{\sigma}(\mathrm{MPa})$ & $\sigma_{0}(\mathrm{MPa})$ & $m$ \\
\hline ML33S & $30<d<100$ & $65 \pm 20$ & $952 \pm 254$ & 1044 & 4.572 \\
HTTS & $30<d<100$ & $61 \pm 24$ & $1001 \pm 256$ & 1122 & 4.462
\end{tabular}

fibers from ML33S and HTTS achieve values of $m>8$, which implies a high reproducibility of the tensile strength of thick monofilaments. For thinner fibers, the Weibull modulus specially in the case of ML33S derived fibers is lower, being $m=$ $\sim 6$, reflecting the high scatter in the strength values for fibers with diameters of about $50 \mu \mathrm{m}$. In accordance with Griffith's observations and analysis, the average strength of the thin fibers was higher than that of thick fibers. The Weibull parameters for the thick and the thin ceramic fibers made from the two precursors are summarized in Table 3.

As the strength of the SiCN ceramic fibers derived from ML33S or HTTS show similar values, it appears that the strength of the ceramic SiCN fibers is independent on the tensile strength of the cured green fibers. The results obtained in this work indicate that the strength of the uncured or cured green fibers is closely related to the chemical properties of the polymer, particularly the molecular weight, the rheology and the functional reactive groups. But in relation to ceramic SiCN fibers, the type of precursor, ML33S or HTTS, does not have significant influence on the strength.

A discussion focused on the dependency of the tensile strength of a polymer derived amorphous ceramic fiber on the fiber diameter, fiber surface and microstructure is rather complex. The strength distribution will depend on the polymer system, the processing history of the green fiber, their curing and pyrolysis conditions. Further investigations are needed including careful analysis of fracture origin in order to improve the strength and strength distribution of fibers made from precursors.

3.2.2. Creep response. The use of ceramic SiCN fibers as reinforcements for MMCs and CMCs for thermomechanical
Table 3 Mean strength and Weibull parameters of ceramic SiCN fibers

\begin{tabular}{llllll}
\hline PDC & Fiber diameter $(\mu \mathrm{m})$ & $\bar{d}(\mu \mathrm{m})$ & $\bar{\sigma}(\mathrm{MPa})$ & $\sigma_{0}(\mathrm{MPa})$ & $m$ \\
\hline \multirow{2}{*}{ ML33S } & $<70$ & $49 \pm 6$ & $1113 \pm 223$ & 1200 & 6.022 \\
& $>70$ & $85 \pm 8$ & $747 \pm 91$ & 785 & 9.957 \\
\multirow{2}{*}{ HTTS } & $<70$ & $36 \pm 6$ & $1268 \pm 187$ & 1348 & 7.957 \\
& $>70$ & $81 \pm 9$ & $802 \pm 110$ & 847 & 8.855
\end{tabular}

applications also requires the investigation of their creep behavior, which was characterized by measuring their Bend Stress Relaxation (BSR) in air and inert atmosphere.

The creep behavior of polymer derived ceramic SiCN fibers, as well as SiC fibers, is correlated to their microstructure and mechanical stability. The factors, which will mainly influence the creep resistance of the ceramic fibers are processing temperature, oxygen and free carbon contents as already discussed in several publications. ${ }^{27-33}$

Fig. 10 demonstrates that both fiber types derived from ML33S and HTTS have similar creep resistance either in air as well as in nitrogen atmosphere. No stress relaxation occurs up to $1000{ }^{\circ} \mathrm{C}$. Comparing the creep response of these fibers to other SiCN fibers, similar behavior is observed for ABSE polycarbosilazane derived SiCN fibers reported by Hacker, ${ }^{11}$ which were pyrolysed at $1300{ }^{\circ} \mathrm{C}$ containing $16 \mathrm{wt} \%$ of oxygen. When the test temperature for the ML33S and HTTS derived ceramic fibers is increased to $1100{ }^{\circ} \mathrm{C}$ the creep relaxation starts leading to decreased $m_{\mathrm{BSR}}$ values. For creep test temperatures higher than $1100{ }^{\circ} \mathrm{C}$, which exceed the processing temperature of the fibers, the $m_{\mathrm{BSR}}$ values drops dramatically due to rearrangements within the amorphous SiCN phases.

Similar to Nicalon SiC fibers, ${ }^{35}$ ML33S and HTTS derived ceramic fibers contain free carbon content up to $\sim 20 \mathrm{~mol} \%$ (Table 4), high oxygen content (see Table 1) but they were pyrolysed at lower temperatures in comparison to Hi-Nicalon or Hi-Nicalon S fibers. ${ }^{37,38}$ However, Nicalon fibers already suffer stress relaxation at $1000{ }^{\circ} \mathrm{C}$ with the evolution of SiO and CO gases due to its microstructure, composed of an amorphous
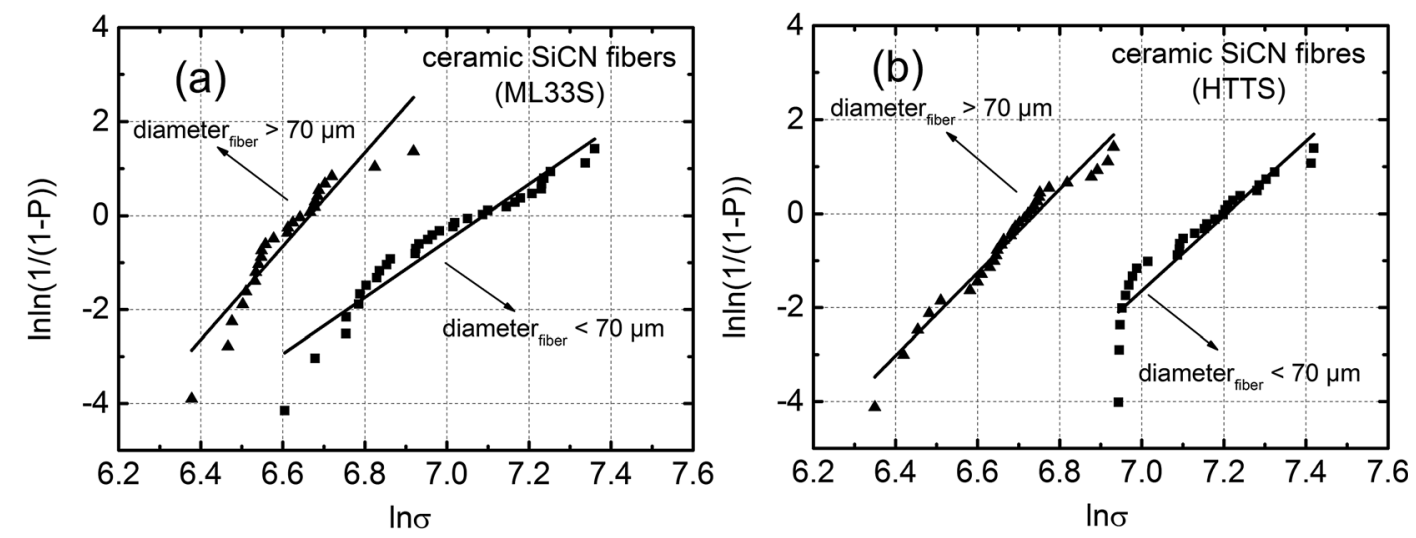

Fig. 9 Weibull plots for (a) ML33S and (b) HTTS derived ceramic SiCN fibers divided in two groups - thin (diameter < $70 \mu \mathrm{m}$ ) and thick (diameter > $70 \mu \mathrm{m})$. 


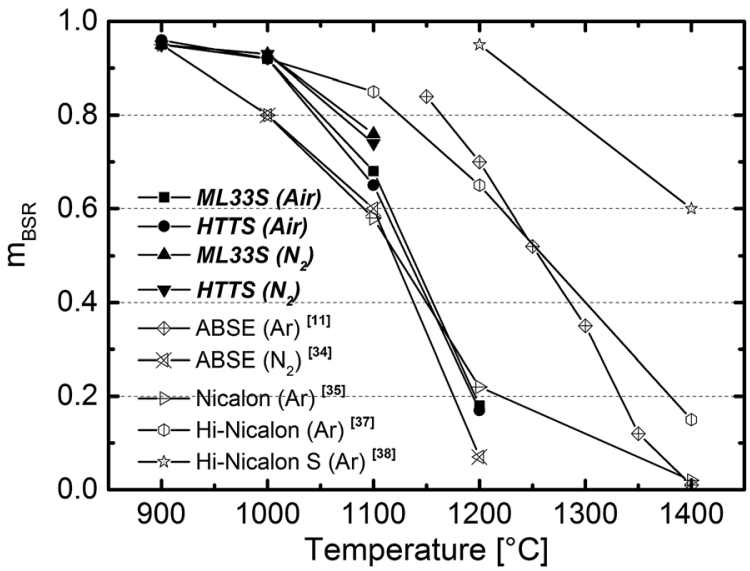

Fig. 10 Bend stress relaxation modulus $\left(m_{\mathrm{BSR}}\right)$ versus temperature for polymer derived ceramic fibers (dwell time at temperature: 1 hour).

SiCO phase, a free carbon phase and small $2-5 \mathrm{~nm} \beta$-SiC crystallites, compromising its creep resistance. ${ }^{35,36}$

In fact the creep resistance of SiCN fibers derived from ML33S and HTTS is similar to that of Hi-Nicalon SiC fibers, although they contain lower levels of oxygen and are processed at higher temperatures of $\geq 1300{ }^{\circ} \mathrm{C}$. The better creep resistance of SiCN fibers in comparison to the oxygen rich Nicalon fibers is due to the stability of the amorphous SiCN phase against crystallization up to $1400{ }^{\circ} \mathrm{C}$. An increase of the pyrolysis temperature for the processing of ML33S and HTTS derived fibers up to $\sim 1300{ }^{\circ} \mathrm{C}$ should also lead to a further increase of the creep resistance, as already demonstrated for ABSE derived ceramic SiCN fibers with about $16 \mathrm{wt} \%$ oxygen. ${ }^{11}$

As the focus of the present work was to develop large diameter SiCN monofilaments, it is instructive to compare the creep resistance of these fibers with other large diameter SiC fibers. Fig. 11 shows the creep resistance of large diameter $(>70 \mu \mathrm{m})$ SiCN fibers from ML33S and HTTS in comparison to commercially available CVD SiC fibers. It can be noted that the $m_{\mathrm{BSR}}$ modulus of the ceramic SiCN fibers prepared in this work is similar to the commercially available SCS-6 fibers and significantly better than that of Sigma fibers. The stress relaxation of Sigma fibers starts at $900{ }^{\circ} \mathrm{C}$ and the $m_{\mathrm{BSR}}$ modulus is 0.8. At $1100^{\circ} \mathrm{C}$ the creep resistance is very low and the BSR modulus is only $\sim 0.1$.

Sigma 1156 fibers are composed of stoichiometric SiC grain near the tungsten core and excess silicon near the surface, which is responsible for the drop of the creep resistance at $T>900{ }^{\circ} \mathrm{C} .{ }^{40}$ In contrast, the $\mathrm{SiC}$ in the SCS- 6 fibers is nearly stoichiometric and chemically stable up to high temperatures. The creep behavior of these fibers in the temperature region $1100<T<1300{ }^{\circ} \mathrm{C}$ is

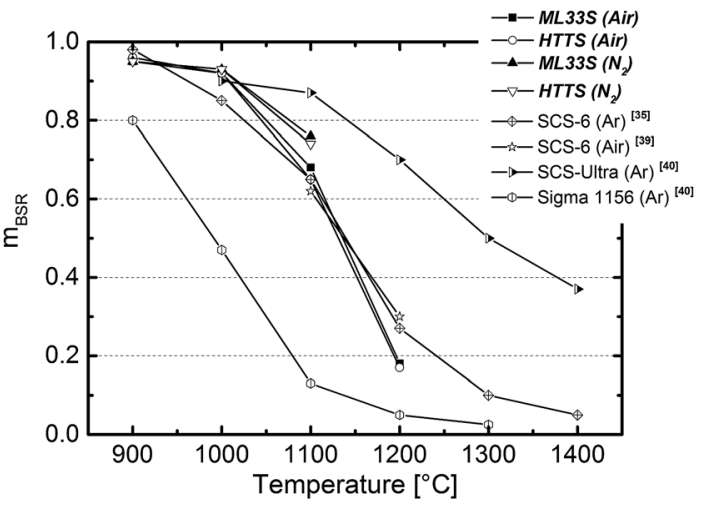

Fig. 11 Bend stress relaxation modulus $\left(m_{\mathrm{BSR}}\right)$ versus temperature for Si-based ceramic fibers with diameter $>70 \mu \mathrm{m}$ (dwell time at temperature: 1 hour).

dominated by microstructural changes in the complex composite structure of these fibers. SCS-6 fibers contain concentric regions with different SiC compositions, free carbon at the grain boundaries and a carbon-rich surface coating. This composite structure induces microstructural changes at high temperatures due to diffusion of free silicon from the near-stoichiometric region with $\beta$-SiC grains into the carbon-rich surface coating, reducing its thermal stability. Above $1300{ }^{\circ} \mathrm{C}$ the thermal degradation starts. ${ }^{39-41}$

The results in this chapter indicate that the more costeffective precursor route for the processing of large diameter ML33S and HTTS derived ceramic SiCN fibers make their use as reinforcement of MMCs very attractive, despite their still limited mechanical properties. Although the maximum pyrolysis temperature of the polymer derived ceramic fibers prepared in this work is only $1100{ }^{\circ} \mathrm{C}$, due to the limited maximum pyrolysis temperature of the furnace, their creep resistance is already comparable to SCS-6 fibers, which are currently the most preferred ceramic monofilaments to reinforce MMCs in spite of their high cost.

3.2.3. Oxidation resistance. The well known high oxidation resistance of $\mathrm{Si}, \mathrm{SiC}$ and $\mathrm{Si}_{3} \mathrm{~N}_{4}$ ceramics is due to the growth of a silica film in the passive regime, protecting the materials against continued oxidation. For all these Si-materials the permeation of $\mathrm{O}_{2}$ through $\mathrm{SiO}_{2}$ governs the oxidation rate. However, in $\mathrm{Si}_{3} \mathrm{~N}_{4}$ ceramics the thickness of the silica layer in the passive regime is lower than that in $\mathrm{Si}$ and $\mathrm{SiC}$ under similar thermal and atmospheric conditions. During the oxidation of $\mathrm{Si}_{3} \mathrm{~N}_{4}$ a duplex $\mathrm{Si}_{2} \mathrm{~N}_{2} \mathrm{O} / \mathrm{SiO}_{2}$ layer is formed. The silicon oxynitride layer acts as a diffusion barrier during oxidation, leading to better oxidation resistance of $\mathrm{Si}_{3} \mathrm{~N}_{4}$ compared to $\mathrm{SiC} .{ }^{42}$

Table 4 Microstructural features of the ceramic SiCN monofilaments

Microstructure

Amorphous silicon (oxy)carbonitride + free carbon

Ceramic from ML33S

Ceramic from HTTS
Amorphous silicon (oxy)carbonitride + free carbon
Stoichiometric formula $\left(T=1100^{\circ} \mathrm{C}\right)$

$\mathrm{SiC}_{0.26} \mathrm{~N}_{0.70} \mathrm{O}_{0.43}+0.43 \mathrm{C}_{\mathrm{f}}$

$\mathrm{SiC}_{0.29} \mathrm{~N}_{0.23} \mathrm{O}_{1.07}+0.67 \mathrm{C}_{\mathrm{f}}$
Free carbon $(\mathrm{mol} \%)$

15.2

20.6 

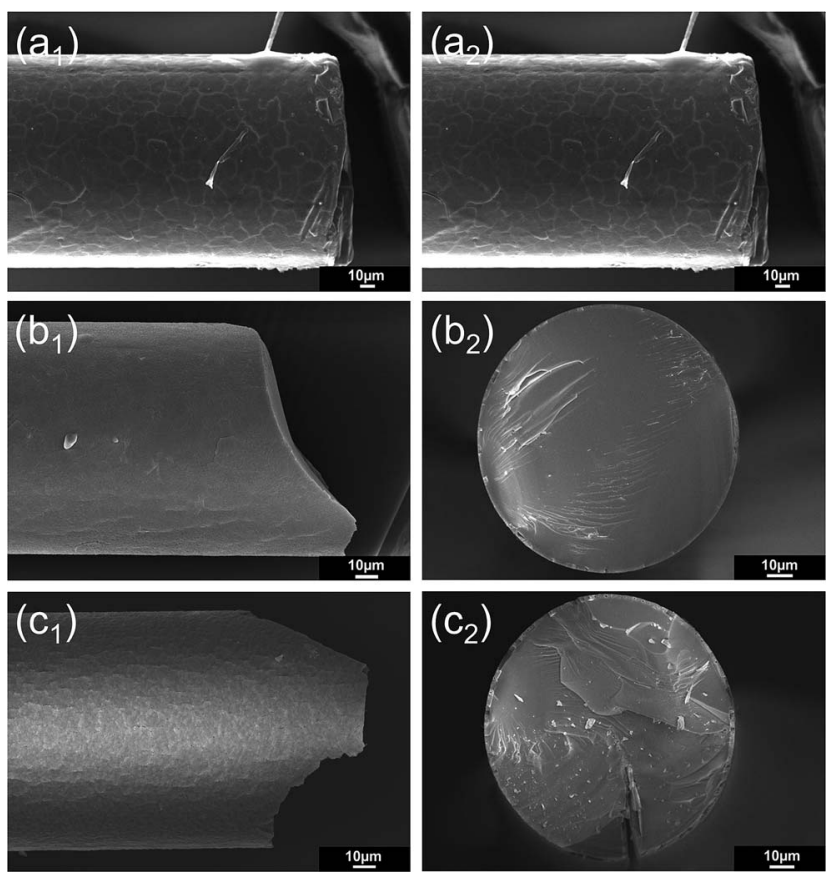

Fig. 12 SEM micrographs of the surface and cross section of ceramic fibers after 12 hours at $1200^{\circ} \mathrm{C}$ in air: (a) CVD SCS- 6 fiber, (b) ML33S and (c) HTTS derived ceramic SiCN fibers.

For the oxidation tests performed in this work, at temperatures between 900 and $1100{ }^{\circ} \mathrm{C}$ in air a thin and smooth passivating $\mathrm{SiO}_{2}$ coating forms on the surface of the fibers (CVD SCS-6, ML33S and HTTS derived ceramic fibers), protecting or reducing the oxidation of the material at these temperatures.
After annealing of the SCS- 6 fibers in air at $1200{ }^{\circ} \mathrm{C}$, an outer $\mathrm{SiO}_{2}$ layer with a thickness of $2.5 \mu \mathrm{m}$ is formed (Fig. 12a). Cracks and pores within the oxide layer already appear after this oxidation test. Additionally, the carbon core is completely oxidized.

In contrast, the oxide layer of the ML33S and HTTS derived fibers formed at the same conditions is smooth and defect free with a thickness between 1.5 and $1.8 \mu \mathrm{m}$ (Fig. 12b and $\mathrm{c}$ and 13).

If ML33S or HTTS derived ceramic fibers are exposed to air at $1300{ }^{\circ} \mathrm{C}$, the outer surface of the $\mathrm{SiO}_{2}$ layer with a thickness of $\sim 3.5 \mu \mathrm{m}$ shows first signs of cracks (Fig. 14b and c). For comparison, the micrographs of the SCS- 6 fiber also oxidized at $1300{ }^{\circ} \mathrm{C}$ are shown in Fig. 14a. The thickness of the resulting oxide layer is with about $3.5 \mu \mathrm{m}$ comparable to our fibers.

The oxidation behavior of the SiCN fibers most likely follows the same mechanisms as reported by Chollon and Mocaer ${ }^{\mathbf{1 0 , 4 3}}$ and later on discussed by Hacker ${ }^{11}$ and Kokott. ${ }^{34}$ The ML33S and HTTS derived ceramic fibers can be considered as $\operatorname{SiCN}(\mathrm{O})$ systems, due to their oxygen contents $>10 \mathrm{wt} \%$. Therefore, the oxidation process in summary follows eqn (04):

$$
\begin{aligned}
\mathrm{SiC}_{x} \mathrm{~N}_{4 y / 3} \mathrm{O}_{2(1-x-y)(\mathrm{s})}+(3 x / 2+y) \mathrm{O}_{2(\mathrm{~g})} \rightarrow \\
\\
\mathrm{SiO}_{2(\mathrm{~s})}+x \mathrm{CO}_{(\mathrm{g})}+2 y / 3 \mathrm{~N}_{2(\mathrm{~g})}
\end{aligned}
$$

(with $0 \leq x \leq x+y \leq 1$ ) for the amorphous $\operatorname{SiC}_{x} \mathrm{~N}_{4 y / 3} \mathrm{O}_{2(1-x-y)}$ phase and, if present, for the free carbon:

$$
\mathrm{C}_{(\mathrm{s})}+1 / 2 \mathrm{O}_{2(\mathrm{~g})} \rightarrow \mathrm{CO}_{(\mathrm{g})}
$$

During the oxidation of $\operatorname{SiCN}(\mathrm{O})$ systems a complex process occurs, involving the oxidation mechanism of both $\mathrm{SiC}$ and $\mathrm{Si}_{3} \mathrm{~N}_{4}$, such as simultaneous evaporation of $\mathrm{CO}$ and $\mathrm{N}_{2}$ by diffusion

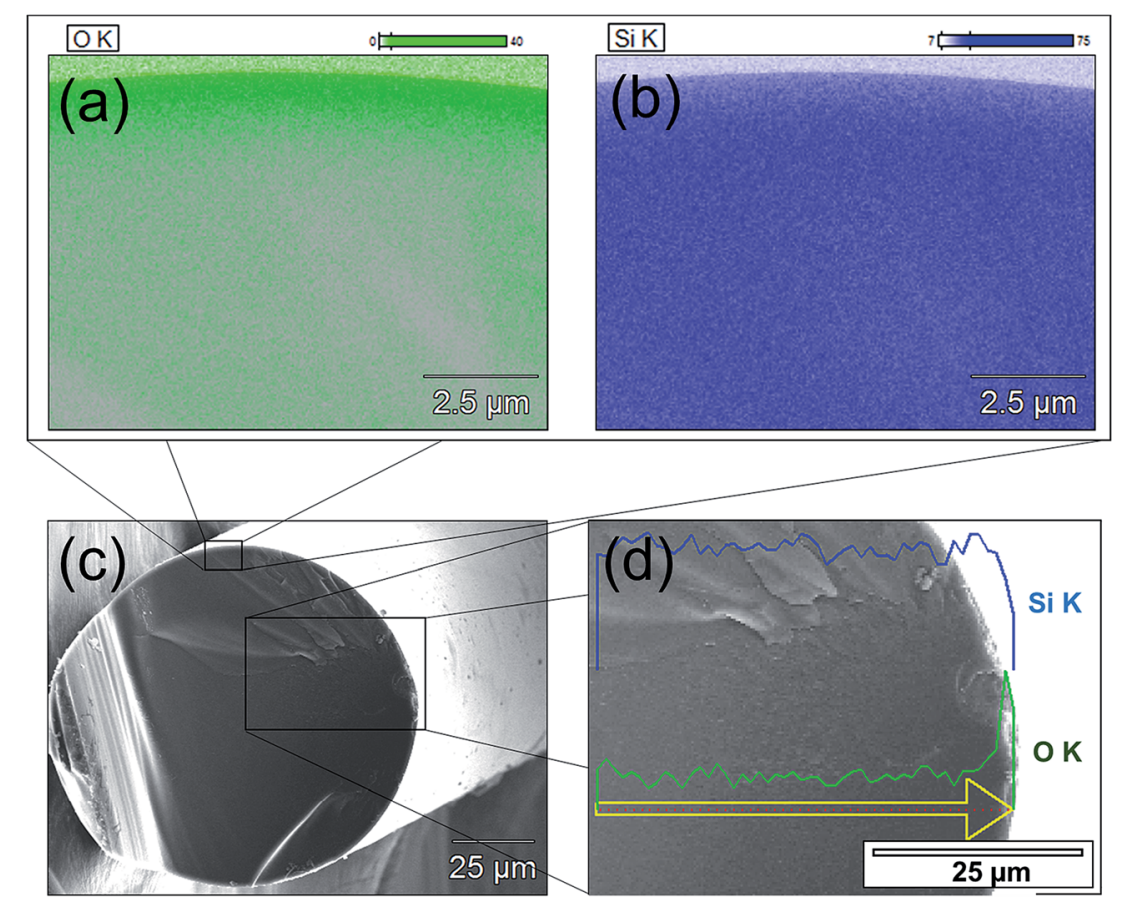

Fig. 13 Energy dispersive spectroscopy (EDS) (a) oxygen map and (b) silicon map of the cross section (SEM micrograph) of a (c) ML33S derived ceramic fiber after 12 hours at $1200{ }^{\circ} \mathrm{C}$ in air with (d) Si $\mathrm{K}$ and $\mathrm{O} \mathrm{K}$ linescan. 

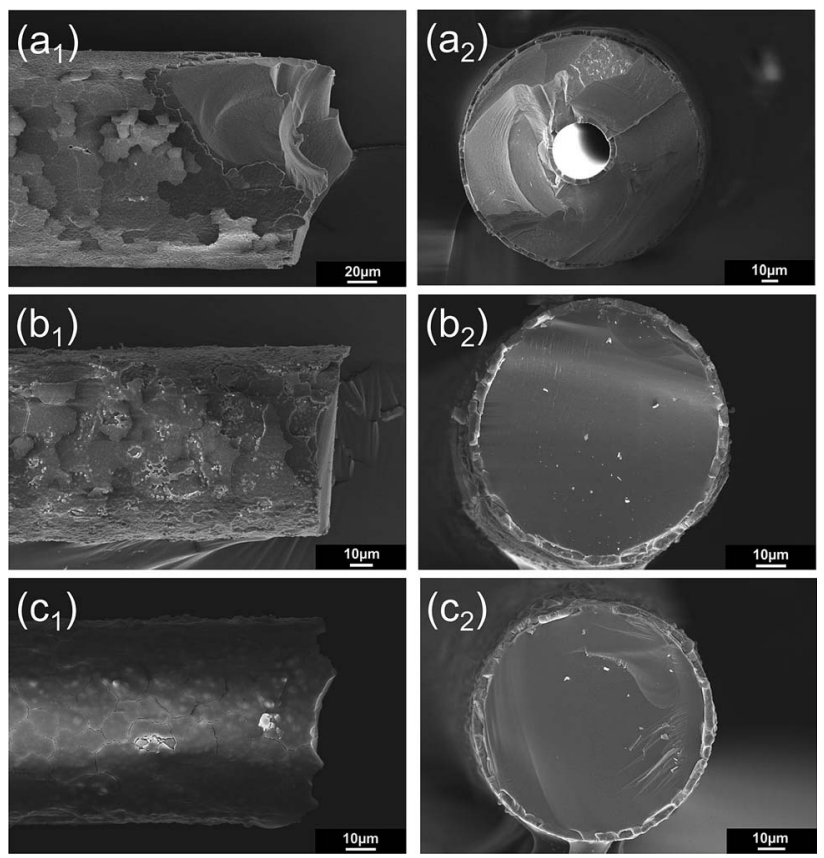

Fig. 14 SEM micrographs of the surface and cross section of ceramic fibers after 12 hours at $1300{ }^{\circ} \mathrm{C}$ in air: (a) CVD SCS- 6 fiber, (b) ML33S and (c) HTTS derived ceramic SiCN fibers.

through the oxide layer. According to Chollon, ${ }^{10}$ the high oxidation stability of $\operatorname{SiCN}(\mathrm{O})$ fibers is due to the formation of a SiCNO interface (composition $\operatorname{SiC}_{(x-\delta x)} \mathrm{N}_{4(y-\delta y) / 3} \mathrm{O}_{2(1-x-y+\delta x+\delta y)}$ ) between the fiber core and the outer $\mathrm{SiO}_{2}$ layer. This interface enables a continuous variation of the concentration from initial $\operatorname{SiCN}(\mathrm{O})$ composition of the ceramic fiber until $\mathrm{SiO}_{2}$. Decisive for the oxidation stability is the necessary activation energy to further oxidize the SiCNO interface, which in this case is considered to be a combination of $\mathrm{Si}_{3} \mathrm{~N}_{4}, \mathrm{SiC}$ and $\mathrm{SiO}_{2}$. The activation energy of the reaction of oxygen with $\mathrm{Si}_{3} \mathrm{~N}_{4}$ is $330-490 \mathrm{~kJ} \mathrm{~mol}^{-1}$, which is much higher than with $\mathrm{SiC}$, being $90-140 \mathrm{~kJ} \mathrm{~mol}^{-1}$. Therefore, the higher the content of $\mathrm{Si}-\mathrm{N}$ bondings in the $\operatorname{SiCN}(\mathrm{O})$ system, the higher is the necessary activation energy for the oxidation reaction of the fiber and finally their oxidation stability.

Thus the oxidation tests indicate that the oxidation resistance of ML33S and HTTS derived ceramic SiCN fibers is higher or comparable to the commercially available SCS-6 fibers despite their low processing temperature of only 1100 ${ }^{\circ} \mathrm{C}$. MMCs and CMCs are generally used to combine thermomechanical stability with oxidation resistance at high temperatures. If voids or cracks are present (or generated) in the matrix, the contact with oxygen degrades the reinforcement, depending on its oxidation resistance. Therefore, carbon fibers, thus also the carbon core of SCS-6 fibers (see Fig. 12a and 14a), are not suitable for high temperature applications in an oxidative atmosphere. In contrast ceramic SiCN fibers are completely protected with passivating oxide layers, which allows their use also in air at higher temperatures.

\section{Conclusions}

Ceramic SiCN fibers with diameters $>70 \mu \mathrm{m}$ were successfully produced via melt-spinning of two recently developed solid polysilazanes from our chair, ML33S and HTTS, curing in inert atmosphere with electron beam irradiation doses up to 1000 kGy and continuous pyrolysis in inert atmosphere. After curing with an electron beam dose of $600 \mathrm{KGy}$, green fibers from ML33S achieve a tensile strength of $43 \mathrm{MPa}$ and a gel content of $60 \%$. Green fibers from HTTS cured with the same electron beam dose show higher strength values of $65 \mathrm{MPa}$ and a gel content of $100 \%$. This is a consequence of the more reactive Sivinyl groups in HTTS, which assures a high level of cross-linking after electron beam treatment already with a low dose of only 200 kGy. The resulting cured green fibers are stronger and more flexible, which is very important for subsequent handling and pyrolysis to ceramic SiCN fibers.

The tensile strength distribution of ceramic SiCN fibers is related to their fiber diameter. Ceramic SiCN fibers with diameters $>70 \mu \mathrm{m}$ achieve a tensile strength of $800 \mathrm{MPa}$, while ceramic SiCN fibers with diameter $<70 \mu$ m yield strength values of $\sim 1.6 \mathrm{GPa}$. The Weibull modulus for the large diameter fibers is rather high $(\sim 8)$ indicating that the strength variability is rather low.

The creep behavior of the ceramic SiCN fibers is influenced by their composition, mainly oxygen and free carbon contents, as well as by the pyrolysis temperature. No stress relaxation is observed for ML33S and HTTS derived ceramic SiCN fibers up to $1000{ }^{\circ} \mathrm{C}$. Up to a temperature of $1100{ }^{\circ} \mathrm{C}$, their creep behavior is similar to that of Nicalon and SCS-6 fibers. At higher temperatures the creep resistance decreases remarkably due to the low pyrolysis temperature of only $1100{ }^{\circ} \mathrm{C}$ and the high oxygen contents (12.9 and $28.6 \mathrm{wt} \%$ ).

The oxidation resistance of ceramic SiCN fibers from ML33S and HTTS is similar or superior than SCS-6 fibers. After a heat treatment in air at $1200{ }^{\circ} \mathrm{C}$ for 12 hours, the surface of the ML33S and HTTS derived ceramic fibers is protected by a close defect free protective silica layer, while the oxidation layer of SCS-6 fibers already show cracks and pores.

For the first time we demonstrated the continuous processing of thick ceramic SiCN fibers by using the PDC technology. There is a high potential to improve the ceramic fiber properties by optimizing the processing parameters, reducing the oxygen content and increasing the pyrolysis temperature. Therefore the developed technology offers a promising route to produce thick ceramic fibers for e.g. the reinforcement of MMCs, especially titanium matrix composites.

\section{Acknowledgments}

The authors thank Ute Kuhn from the Polymer Engineering Institute and Andre Prette, University of Bayreuth, for the TGA and DSC measurements, and Fraunhofer Institute HTL, Bayreuth, for mechanical tests of the fibers. We also thank Deutsche Forschungsgemeinschaft (DFG) for supporting this work within the project SiMet. RKB acknowledges the Humboldt Research Award which was responsible for initiating this collaboration. 


\section{References}

1 T. T. Cheng, I. P. Jones, R. A. Shatwell and P. Doorbar, Mater. Sci. Eng., A, 1999, 260, 139-145.

2 O. Flores, R. K. Bordia, D. Nestler, W. Krenkel and G. Motz, Adv. Eng. Mater., 2014, 16, 621-636.

3 S. R. Nutt and F. E. Wawner, J. Mater. Sci., 1985, 20, 19531960.

4 A. R. Bunsell and A. Piant, J. Mater. Sci., 2006, 41, 823-839.

5 J. A. DiCarlo and H. M. Yun, Handbook of Ceramic Composites, Springer, New York, 2005, pp. 33-52.

6 G. Motz and R. K. Bordia, Handbook of textile fibre structure Volume 2: Natural, regenerated, inorganic and specialist fibres, Woodhead Publishing Ltd., Cambridge, UK, 2009, pp. 378-424.

7 M. Herkt, F. Heutling and U. Koch, Adv. Eng. Mater., 2004, 6, 761-767.

8 C. Leyens, J. Hausmann and J. Kumpfert, Adv. Eng. Mater., 2003, 5, 399-410.

9 P. Martineau, R. Pailler, M. Lahaye and R. Naslain, J. Mater. Sci., 1984, 19, 2749-2770.

10 G. Chollon, J. Eur. Ceram. Soc., 2000, 20, 1959-1974.

11 J. Hacker, Entwicklung einer preiswerten keramischen Faser für den Anwendungsbereich bis 1400 Grad Celsius auf der Basis eines spinnfähigen siliciumorganischen Polymers, Utz, München, 2006.

12 O. Flores, T. Schmalz, W. Krenkel, L. Heymann and G. Motz, J. Mater. Chem. A, 2013, 1, 15406-15415.

13 O. Flores, L. Heymann and G. Motz, Rheo. Acta, 2015, 54, 517-528.

14 G. Motz, D. Decker and T. Schmalz, EP Patent, 12006145, 2012.

15 DIN 16892 - Rohre aus vernetztem Polyethylen hoher Dichte (PE-X) Allgemeine Guteanforderungen, Prüfung, 6.5. Vernetzungsgrad, 2000.

16 DIN EN 1007-4 - Hochleistungskeramik - Keramische Verbundwerkstoffe: Faserverstärkungen; Teil 4: Bestimmung der Zugeigenschaften von Fasern bei Raumtemperatur, 1994.

17 G. N. Morscher and J. A. DiCarlo, J. Am. Ceram. Soc., 1992, 75, 136-140.

18 G. Motz, T. Schmalz, S. Trassl and R. Kempe, Design, Processing and Properties of Ceramic Materials from Preceramic Precursors, Nova Science Publishers Inc., Hauppauge USA, 2011, pp. 15-35.

19 T. Taki, K. Okamura, M. Sato, T. Seguchi and S. Kawanishi, J. Mater. Sci. Lett., 1988, 7, 209-211.
20 Z. Y. Chu, Y. C. Song, Y. S. Xu and Y. B. Fu, J. Mater. Sci. Lett., 1999, 18, 1793-1795.

21 A. Idesaki, M. Narisawa, K. Okamura, M. Sugimoto, Y. Morita, T. Seguchi and M. Itoh, Radiat. Phys. Chem., 2001, 60, 483-487.

22 S. Kokott and G. Motz, Soft Mater., 2007, 4, 165-174.

23 D. Mocaer, R. Pailler, R. Naslain, C. Richard, J. P. Pillot, J. Dunogues, C. Darnez, M. Chambon and M. Lahaye, J. Mater. Sci., 1993, 28, 3049-3058.

24 A. A. Griffith, Philos. Trans. R. Soc. London, 1921, 221, 163199.

25 W. Weibull, J. Appl. Mech., 1951, 18, 293-297.

26 S. van der Zwaag, J. Test. Eval., 1989, 17, 292-298.

27 G. Chollon, R. Pailler, R. Naslain, F. Laanani, M. Monthioux and P. Olry, J. Mater. Sci., 1997, 32, 327-347.

28 G. Chollon, R. Pailler, R. Naslain and P. Olry, J. Mater. Sci., 1997, 32, 1133-1147.

29 P. le Coustumer, M. Monthioux and A. Oberlin, J. Eur. Ceram. Soc., 1993, 11, 95-103.

30 T. Mah, N. L. Hecht, D. E. McCullum, J. R. Hoenigman, H. M. Kim, A. P. Katz and H. A. Lipsitt, J. Mater. Sci., 1984, 19, 1191-1201.

31 G. Simon and A. R. Bunsell, J. Mater. Sci., 1984, 19, 36583670 .

32 O. Delverdier, M. Monthioux, D. Mocaer and R. Pailler, J. Eur. Ceram. Soc., 1994, 14, 313-325.

33 M. Monthioux and O. Delverdier, J. Eur. Ceram. Soc., 1996, 16, 721-737.

34 S. Kokott-Wenderoth, Herstellung und Charakterisierung Multiwall-Carbon-Nanotube-verstärker keramischer SiCNFasern, Cuvillier Verlag, Göttingen, 2009.

35 R. E. Tressler, Composites, Part A, 1999, 30, 429-437.

36 S. M. Johnson, R. D. Brittain, R. H. Lamoreaux and D. J. Rowcliffe, J. Am. Ceram. Soc., 1988, 71, C-132-C-135.

37 G. N. Morscher and J. A. DiCarlo, Proceedings of the NASA 6th Annual HITEMP Review, Cleveland, OH, 1993.

38 M. Takeda, J. Sakamoto, A. Saeki and H. Ichikawa, Ceram. Eng. Sci. Proc., 1996, 17, 35-43.

39 G. N. Morscher, C. A. Lewinsohn, C. E. Bakis and R. E. Tressler, J. Am. Ceram. Soc., 1995, 78, 3244-3252.

40 G. Chollon, R. Naslain, C. Prentice, R. Shatwell and P. May, J. Eur. Ceram. Soc., 2005, 25, 1929-1942.

41 R. T. Bhatt and D. R. Hull, J. Am. Ceram. Soc., 1998, 81, 957964.

42 H. Du, R. E. Tressler, K. E. Spear and C. G. Pantano, J. Electrochem. Soc., 1989, 136, 1527-1536.

43 D. Mocaer, G. Chollon, R. Pailler, L. Filipuzzi and R. Naslain, J. Mater. Sci., 1993, 28, 3059-3068. 